It is thought that the efficacy of D.D.T. and benzene hexachloride is probably due, at least in part, to the habit of the Syringopais larva of leaving its mine and re-entering the same or another leaf, its movement thus bringing it in contact with an insecticide on the surface of the leaves. D.N.O.C. appeared to affect the larvæ in their mines.

The simple duster described by Staniland and Major ${ }^{1}$ has been found most suitable for use by peasant farmers in applying the insecticidal dusts to the growing crop. These control measures have been demonstrated in many places in Cyprus during the past two seasons and are finding acceptance with the farmers.

The collaboration of other members of this Department in carrying out these trials is gratefully acknowledged. It is hoped to publish a fuller account of this work elsewhere.

Department of Agriculture,

H. M. MORRIS

Nicosia, Cyprus.

Nov. 21.

${ }^{\prime}$ Staniland, L. N., and Major, J., Agriculture, 54, 11 (Feb. 1948).

\section{Blood-Group Frequencies in Auckland, New Zealand}

Buood samples from 2,802 donors in greater Auckland City were tested for their $A B O$ and $R h(D)$ groups with the following results :

$\begin{array}{ccccccc}O & A & B & A B & p & q & \\ 1,487 & 996 & 247 & 72 & 0 \cdot 2126 & 0 \cdot 581 & 0 \cdot 7284 \\ (53 \cdot 07 \%) & (35 \cdot 54 \%) & (8 \cdot 81 \%) & (2 \cdot 57 \%) & & & \end{array}$

84.4 per cent of the total were agglutinated by anti- $D$ antisera.

Of $669 A$ bloods, 544 (81.3 per cent) were $A_{1}$ and 125 (18.7 per cent) $A_{2}$, giving a frequency for $p 1$ of 0.1686 and for $p 2$ of 0.044 .

$67 A B$ bloods were $A$ subgrouped and $54(80.6$ per cent) were found to be $A_{1} B$ and 13 (19.4 per cent) $A_{2} B$.

The expected frequencies of $A_{1} B$ and $A_{2} B$ in the population may be calculated from the estimated values of $p 1, p 2$ and $q$, and these show a reasonable agreement with the observed frequencies.

$$
\begin{array}{ccc} 
& A_{1} B & A_{2} B \\
\text { Observed } & 2.07 \text { per cent } & 0.49 \text { per cent } \\
\text { Expected } & 1.94
\end{array}
$$

Godley ${ }^{1}$ analysed the $A B O$ groups of 1,176 white New Zealand soldiers recorded at the time of mobil. ization. His figures are :

$\begin{array}{ccccccc}o & A & B & A B & p & q & r \\ 47 \cdot 11 \% & 39 \cdot 28 \% & 10 \cdot 28 \% & 3 \cdot 31 \% & 0 \cdot 2431 & 0 \cdot 0712 & 0 \cdot 6863\end{array}$

One of us, while engaged in check groupings on soldiers in the Army Transfusion Service in the Middle East in 1943, found an error in the mobilization groupings of up to 10 per cent in the determination of group $O$, due to the use of improperly selected anti- $A$ and anti- $B$ grouping sera, and to the use of a technique which did not allow the recognition of rouleaux, or prevent false agglutination due to infection. Also, the serum of the individual was not tested for its agglutinin content. Thus the Army groupings were unreliable.

A further deviation of the Army frequencies from the Auckland frequencies given here would probably be expected, as the latter do not represent the whole population of New Zealand.

\section{J. M. Staveley}

E. J. Godley

Auckland Hospital,

New Zealand. Nov. 11.

1 Ann. Eugen., 13, 2, 99 (1945).

\section{Statistical Studies of Zircon as a Criterion in Granitization}

THE opposing views of magmatists and transformists have resulted in a heated controversy on the origin of granite, and a recent conference on this question held by the Geological Society of America ${ }^{1}$ has stressed the importance of criteria for distinguishing between granite formed in situ and granite formed elsewhere and intruded in new surroundings. It has been demonstrated repeatedly that criteria, formerly regarded as incontrovertible, are open to debate. Indeed, there do not appear to be any established criteria which both magmatists and transformists will accept as decisive.

In favourable instances, statistical studies of zircons may yield criteria establishing the type and origin of granite. Such studies include observations on the colour, crystal habit and elongation ratio of the zircons. Elongation - frequency curves ${ }^{2}$ of zircons, in particular, may provide valuable clues regarding the origin of granite. Representative results have been obtained by measurement of three hundred crystals for each rock ${ }^{3}$. Zircons of intrusive granites may be expected to consist mainly of sharply terminated prismatic crystals. By virtue of their crystal form, elongation - frequency curves would normally show a maximum at an elongation ratio greater than $2 \cdot 0$. Zircons of sediments, on the other hand, are frequently rounded, and elongation-frequency curves normally show a maximum at an elongation ratio less than $2 \cdot 0$. Static granites formed in situ from such sediments may contain a majority of either rounded zircons, or of sharply terminated zircons. In the latter case the granitization series should show evidence of the recrystallization of the rounded crystals to the well-formed, magmatic zircons. Observations made by von Backström and $\mathrm{me}^{4}$ indicate that zircons may indeod recrystallize under ultra-metamorphic conditions. Two hypothetical examples further illustrate the applications of the method.

In the first example (Fig. 1) granite intrusive into sedimentary rocks has formed migmatites by lit-par-lit injection and imbibition. The zircons of the sediments are rounded, those of the granite well-formed and typically magmatic. The migmatites, consisting

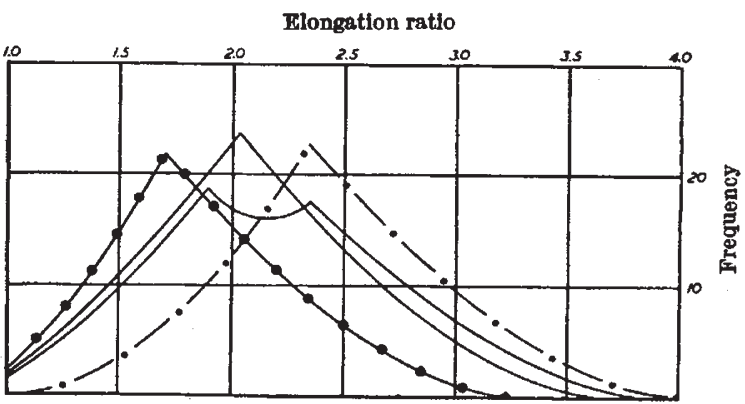

Fig. 1. - - - Intrusive granite; $\bullet-\bullet-$, sediment ; 